\title{
Alerts for policy makers extracted from papers published during 2012 in volume 4 of Food Security
}

\author{
Richard Strange
}

Received: 13 December 2012 / Accepted: 18 December 2012 / Published online: 5 January 2013

(C) Springer Science+Business Media Dordrecht and International Society for Plant Pathology 2013

The salient points of papers published in this volume of Food Security are listed below. It is hoped that they will be noted by Policy Makers concerned with food security and that they will inspire early action. (Numbers after each entry refer to relevant pages in Volume 4 of the journal).

\section{The physical environment}

1. Pressure on land in Kenya: T. S. Jayne and Milu Myanga draw attention to the sharp decline in productivity in Kenya when populations rise above 600-650 persons per $\mathrm{km}^{2}$. They suggest that there is scope for promoting equitable access to arable land that is still unutilized through investment in infrastructure (pp. 399-421).

2. Soil fertility and persistent food insecurity: Emma Stephens and associates draw attention to the poverty trap engendered by low soil fertility and consequent low productivity and food insecurity (pp. 423-439).

3. Socio-economic and political factors in relation to drought vulnerability: Elisabeth Simelton and associates show that rice, wheat and maize production in middle income countries are particularly vulnerable to drought. Moreover, vulnerability was greater in authoritarian régimes and flawed democracies than hybrid régimes and full democracies (pp. 163-179).

4. Land and water availability in India: M. Dinesh Kumar and co-authors point out that there is a mismatch between the availability of arable land and water. They suggest as correctives, the judicious investment in surface water projects which encourage direct irrigation, replenishment of over-exploited aquifers, better use of

R. Strange $(\bowtie)$

Birkbeck College, University of London, Malet Street,

WC1E 7HX, London, UK

e-mail: r.strange@sbc.bbk.ac.uk green water and a shift to low water consuming crops (pp. 539-556).

5. Rainfall variability: Mintewab Bezabih and Salvatore Di Falco found that the uncertainty of rainfall prevented farmers from choosing high risk - high return crops and suggest that this could be mitigated by weather insurance policies and crop diversification (pp. 557-567).

The biological environment: productivity and consumption

1. Crops that feed the World: Two crops are reviewed in this series: rice is reviewed by P.A. Seck and associates (pp. 7-24) and potato by Paul Birch and associates (pp. 477-508). Policy makers may wish to consider the feasibility of planting these important and nutritious crops in new areas.

2. Hillside growth of maize in Nepal: Prasad Tiwari and associates found that the availability of light limited the yield of maize in agroforestry systems in Nepal. They suggest that this and their other findings may be helpful to breeders in developing maize genotypes suitable for the complex hillside systems of Nepal (pp. 103-114)

3. Sorghum production and consumption in India: Basavaraj Gali and Pingali Rao draw attention to the decline in consumption of sorghum in India over a period of about 30 years, although it is still an important crop in the states of Maharashtra, Karnataka and Andhra Pradesh. As there are considerable shortfalls of the better quality rabi type, it is suggested that research should be devoted to increasing its production and that it should be made available through the Public Distribution System to poorer sections of communities (pp. 209-217). 
4. Significance of wild edible fruit diversity in East India: Ajay Mahapatra and Pratap Panda demonstrate the presence of 56 wild edible species of fruit trees in Orissa State and their essential role in the nutrition of tribal households where the average annual consumption is $73 \mathrm{Kg}$ (pp. 219-234).

5. Impact of Nerica rice adoption in the Gambia: Lamin Dibba and associates show that Nerica rice (New Rice for Africa, a cross between Oryza sat$i v a$ and $O$. glaberrima) increased yields and annual income of small-scale rice farmers by $157 \mathrm{~kg}$ per hectare and \$148, respectively (pp. 253-265).

6. Post-harvest losses of maize in Africa: Tadele Tefera demonstrates that post-harvest losses of maize in Africa are between 14 and $36 \%$ and that the remaining crop may be poisoned by mycotoxins. To combat these problems, he advocates maintenance of low moisture content of grains, the use of high yielding maize with resistance to post-harvest pests and the use of super grain bags or metal silos (pp. 267-277).

7. Yield gaps: James Sumberg points out that although the concept of "yield gap" is a useful one, it should be carefully defined. Is it between what the farmer actually obtains and economic or technical yield in the field or is it between actual and the maximum yield obtained at a research station or the calculated potential yield? (pp. 509-518)

8. Crop losses: Serge Savary and associates call attention to the difficulty in measuring the losses of crops to plant diseases. Although direct losses may be substantial, there are also other losses which may not be so obvious such as loss of quality and contamination by toxins, and the expense of developing new varieties which, owing to the occurrence of new pathogens or new virulences of established pathogens, have short productive lives (pp. 519-737).

9. Seed Security: Louise Sperling and Shawn McGuire contend that issues of access and the contribution to commercial and livelihood bases of seed must be addressed. They advocate refraining from using the general phrase 'seed secure' but rather to qualify it in relation to a specific goal such as 'seed secure to ensure income generation' (pp. 569-579)

10. Post-harvest storage technology: Raushan Bokusheva and associates report on the success in adoption of metal silos for maize storage in four Central American countries and that adopting households experienced a significantly higher improvement in their well-being compared with non-adopters (pp. 279-293).
The socio-political and economic environment

Governance

1. Cash Transfers: Sebastian Levine suggests that cash transfers would have been a more effective way of reducing poverty and in shielding Namibians from the worst impact of the food price crisis of 2007/2008 (pp. 59-71).

2. Smallholders' access to agricultural credit: Abid Hussain and Gopal Thapa found that a government scheme to make credit available to smallholder farmers for inputs such as farm machinery, fertilizer and seed was most effective for those with comparatively large holdings (2.5-5.0 acres) and least effective for those with small holdings $(\leq 1.0$ acre). They suggest that the government should improve access of all smallholders to credit, particularly those whose holdings are small (pp. 73-85).

3. Household food insecurity in small municipalities of Northeastern Brazil: Rodrigo Pinheiro de Toledo Vianna and associates found that the Brazilian Household Food Insecurity Scale (EBIA), which had previously been validated at the national and urban levels was also valid for municipalities of fewer than 50,000 inhabitants (pp. 295-303). They suggest therefore that EBIA has great potential as a valid tool for targeting and evaluating food security programmes in small and disadvantaged municipalities in Brazil and elsewhere in Latin America and the Carribean.

4. Challenges and opportunities for enhancing food security in Kenya: Gordon Hickey and associates, in their introduction to the special issue on Kenya, published in September 2012, make the point that for food initiatives to be effective, they must involve solutions that are equitable, generalizable and ecologically sound in order to ensure sustainability (pp. 333-340).

5. Cash, food or vouchers: Hope Michelson and associates found that, in rural areas, female-headed households with physical limits to market access strongly preferred food aid to cash or vouchers, while such households in urban areas preferred the flexibility of cash or vouchers to food aid (pp. 455-469).

6. Integrated agricultural research in Eastern Zimbabwe: Kefasi Nyikahadzoi and associates advocate an integrated approach to embed agricultural research and development organizations in a network to undertake multidisciplinary and participatory research. They argue that this is more likely to enhance food security of smallholder farmers than a linear approach from researchers through extension workers, farmers, agro-processors and marketers to consumers (pp. 647-656). 
7. Missing ecological and health dimensions in the Asian food security debate: Mark Wahlqvist and associates state that there should be greater emphasis on family planning, encouragement of plant based diets and creation of resilient regional food systems in order to solve the daunting problem of food security in the area (pp. 657-670).

Nutrition and gender

1. Undernutrition in India: Derek Headey and associates advocate multisectoral approaches to this problem involving commitment at a political level and at the community level to monitor implementation (pp. 87-102).

2. Malnutrition of children in Malawi: Maria Sassi draws attention to the seasonal nature of hunger in Malawi owing to insufficient productivity, exacerbated by volatile food prices in the market on which families are dependent. Their study suggests that improving child nutritional status would require stabilization of maize prices (pp. 593-206).

3. Female-headed households and food insecurity in Brazil: Erica Felker-Kantor and Charles Wood show that although female headed households were more likely to experience moderate or severe food insecurity than those headed by men, women's spending patterns were more favourable to the welfare of children and other members of the household (pp.697-617).

4. Vegetable breeding in Africa: Victor Afari-Sefa and associates found that public sector research supported by a nascent private seed supply sector are resulting in the release of many indigenous and standard vegetables that are nutrient dense. It is suggested that these have considerable potential for reducing poverty and malnutrition on the African continent (pp. 115-127).

5. Homestead food production: As a result of a study of the relationship of dietary diversity and food variety scores to vegetable production and the socio-economic status of women in Tanzania, Gudrun Keding and associates suggest that homestead food production may be a good way to improve dietary diversity (pp. 129-140).
Crises

1. Performance of the Food Security Cluster: Daniel Maxwell and John Parker review the performance of the Food Security Cluster in food security crises with the Haiti volcano of 2010, the Pakistan floods of 2010 and the widespread violence in Kenya in 2008 and in Côte d'Ivoire in 2010 following contested presidential elections. They suggest that the limited availability of qualified individuals and high turn-over of staff were the biggest constraints to effective coordination and emphasize the importance of good leadership (pp. 25-40).

2. The dire food security situation in the Himalayas: Prakash Tiwari and Bhagwati Joshi, in a study of the Kumaon Himalaya, draw attention to a massive decline in per capita food production, decrease in off-farm employment and decrease in remittances from migrants. To remedy the situation, they advocate a community oriented framework for the management of land, water and forest resources and the generation of off-farm employment (pp. 195-207).

3. The dire food security situation in urban poor households in Mumbai, India: Nilesh Chatterjee and associates found that $59.7 \%$ of households in this area were severely food-insecure and state that food security policies and programmes have to be implemented immediately in order to ensure that subsidies and food items are allocated to the households of the vulnerable urban poor (pp. 619-632).

4. Impacts of rises in staple food prices: Andrew Dorward reports that increases in prices of staple foods have had very serious effects on large numbers of poor in national and local economies and states that there is a need for policies and action to address this (pp. 633-645).

5. Out-migration from rural Nepal: Hom Gartaula and associates found that voluntary out-migration from rural areas of Nepal in order to take up remunerative employment elsewhere threatens the role of agriculture and food security in the country (pp. 181-194). 